\title{
Effect of complications within 90 days on patient-reported outcomes 3 months and 12 months following elective surgery for lumbar degenerative disease
}

\author{
Silky Chotai, MD,,2 Scott L. Parker, MD,,2 Ahilan Sivaganesan, MD,,2 J. Alex Sielatycki, MD,,2 \\ Anthony L. Asher, MD, ${ }^{3}$ Matthew J. McGirt, MD, ${ }^{3}$ and Clinton J. Devin, MD ${ }^{1,2}$ \\ Departments of ${ }^{1}$ Orthopaedic Surgery and ${ }^{2}$ Neurological Surgery, Vanderbilt University Medical Center, Nashville, Tennessee; \\ and ${ }^{3}$ Department of Neurological Surgery, Carolina Neurosurgery \& Spine Associates, Charlotte, North Carolina
}

\begin{abstract}
OBJECT There is a paradigm shift toward rewarding providers for quality rather than volume. Complications appear to occur at a fairly consistent frequency in large aggregate data sets. Understanding how complications affect long-term patient-reported outcomes (PROs) following degenerative lumbar surgery is vital. The authors hypothesized that 90-day complications would adversely affect long-term PROs.
\end{abstract}

METHODS Nine hundred six consecutive patients undergoing elective surgery for degenerative lumbar disease over a period of 4 years were enrolled into a prospective longitudinal registry. The following PROs were recorded at baseline and 12-month follow-up: Oswestry Disability Index (ODI) score, numeric rating scales for back and leg pain, quality of life (EQ-5D scores), general physical and mental health (SF-12 Physical Component Summary [PCS] and Mental Component Summary [MCS] scores) and responses to the North American Spine Society (NASS) satisfaction questionnaire. Previously published minimum clinically important difference (MCID) threshold were used to define meaningful improvement. Complications were divided into major (surgical-site infection, hardware failure, new neurological deficit, pulmonary embolism, hematoma and myocardial infarction) and minor (urinary tract infection, pneumonia, and deep venous thrombosis).

RESULTS Complications developed within 90 days of surgery in 13\% (118) of the patients (major in 12\% [108] and minor in 8\% [68]). The mean improvement in ODI scores, EQ-5D scores, SF-12 PCS scores, and satisfaction at 3 months after surgery was significantly less in the patients with complications than in those who did not have major complications (ODI: $13.5 \pm 21.2$ vs $21.7 \pm 19,<0.0001$; EQ-5D: $0.17 \pm 0.25$ vs $0.23 \pm 0.23, p=0.04$; SF-12 PCS: $8.6 \pm 13.3$ vs $13.0 \pm$ $11.9,0.001$; and satisfaction: $76 \%$ vs $90 \%, p=0.002$ ). At 12 months after surgery, the patients with major complications had higher ODI scores than those without complications ( $29.1 \pm 17.7$ vs $25.3 \pm 18.3, p=0.02$ ). However, there was no difference in the change scores in ODI and absolute scores across all other PROs between the 2 groups. In multivariable linear regression analysis, after controlling for an array of preoperative variables, the occurrence of a major complication was not associated with worsening ODI scores 12 months after surgery. There was no difference in the percentage of patients achieving the MCID for disability (66\% vs $64 \%$ ), back pain (55\% vs $56 \%$ ), leg pain ( $62 \%$ vs $59 \%$ ), or quality of life (19\% vs $14 \%)$ or in patient satisfaction rates (82\% vs $80 \%)$ between those without and with major complications. CONCLUSIONS Major complications within 90 days following lumbar spine surgery have significant impact on the short-term PROs. Patients with complications, however, do eventually achieve clinically meaningful outcomes and report satisfaction equivalent to those without major complications. This information allows a physician to counsel patients on the fact that a complication creates frustration, cost, and inconvenience; however, it does not appear to adversely affect clinically meaningful long-term outcomes and satisfaction.

http://thejns.org/doi/abs/10.3171/2015.8.FOCUS15302

KEY WORDS spine surgery; lumbar; patient-reported outcomes; complications; clinically significant; satisfaction

ABBREVIATIONS BMI = body mass index; $B P=$ back pain; $\mathrm{LP}=$ leg pain; $\mathrm{MCID}=$ minimum clinically significant difference; $\mathrm{MCS}=$ Mental Component Summary; $\mathrm{MI}=$ myocardial infarction; ODI = Oswestry Disability Index; PCS = Physical Component Summary; PRO = patient-reported outcome.

SUBMITTED June 1, 2015. ACCEPTED August 27, 2015.

INCLUDE WHEN CITING DOI: 10.3171/2015.8.FOCUS15302. 
$\mathrm{L}$ UMBAR degenerative disorders are highly prevalent in the United States. ${ }^{6,8,13,23,24}$ Although, a select group of patients benefit from non-operative management, a considerable number of patients require surgical treatment to restore functional capacity. ${ }^{29}$ The rates of lumbar surgery for spinal pathology have increased by at least $220 \%$ over the past 2 decades. ${ }^{8}$ Several prospective and randomized controlled trials have shown the efficacy of surgical treatment in degenerative lumbar disease. ${ }^{31,35}$ However, other studies have shown that up to $25 \%$ of patients experience minimal improvement in quality of life and a significant number of patients develop major complications or hospital readmissions following lumbar spine surgery. ${ }^{17,19,32}$ Complications appear to occur at a fairly consistent frequency in large aggregate data sets. 3,4,17,30,32 Previous studies have reported complication rates between $10 \%$ and $20 \% .{ }^{26}$

Current health care systems and physician reimbursements are rapidly transitioning from the "fee-for-service" to the "pay-for-performance" model, resulting in a paradigm shift toward rewarding providers for quality rather than volume. The Institute of Medicine has emphasized that safety, patient-centered outcomes (quality), and cost of care are the key components of value-based health care..$^{22}$ Prospective registries have emerged as a feasible avenue to capture the real-world effectiveness via patient-reported outcomes (PROs) incorporating patients' general health status, quality of life, disease specific health, societal productivity, and satisfaction with care. Complications within 90 days following surgery has been used by administrative databases for over a decade to track quality of care due to ease of acquiring the information. Numerous studies have reported the incidence of perioperative complications and the factors associated with occurrence of complications following elective lumbar spine surgery for degenerative spine pathology. $1,2,4,10,14,16,30,33$ However, there is a paucity of data reporting on the impact of complications within 90 days on long-term PROs., ${ }^{3,18}$ Therefore, understanding how complications affect PROs 12 months following degenerative lumbar surgery is vital. In the present analysis, we hypothesized that major complication within 90 days after surgery would adversely affect long-term PROs in comparison with PROs in a cohort of patients who did not experience a major complication.

\section{Methods}

Patients undergoing elective lumbar surgery for degenerative spine pathology at a single comprehensive spine center (Vanderbilt University Medical Center) over a period of 4 years were enrolled into a prospective, Web-based longitudinal registry. The inclusion criteria for the study were 1) patient age $>18$ years, 2) presentation with back and leg pain, 3) correlative imaging findings for the diagnoses of stenosis, disc herniation, and spondylolisthesis, 4) number of levels operated on $\leq 4$, and 5) failure of 3 months of multimodal non-operative care. The exclusion criteria were 1) any pathological spinal disease (including spine tumor and trauma), 2) an active medical or workman's compensation lawsuit, 3) any extraspinal cause of back or leg pain, 4) being unwilling or unable to partici- pate in the follow-up questionnaires, and 5) lack of availability of complete preoperative variables and follow-up data. All the surgeons participating in this study practiced similar postoperative treatment paradigms. In all cases, the surgeon encouraged discharge from the hospital beginning 48 hours after surgery, weaning from narcotics beginning 2-3 weeks after surgery, and return to work as soon as the patient felt capable.

\section{Outcome Measures}

Patient-reported outcomes for disability, pain, quality of life, and satisfaction were recorded at baseline and at 3 months and 1 year after surgery. The outcomes were assessed via phone interview conducted by an independent data coordinator not involved with clinical care. PRO instruments included 1) the Oswestry Disability Index $(\mathrm{ODI})^{11}$ for back-related disability, 2) the EQ-5D ${ }^{9}$ for quality of life, 3) the SF-12 Physical Component Summary (PCS) and Mental Component Summary (MCS ${ }^{34}$ for general health, 4) numeric rating scales (NRSs) for back pain (BP) and leg pain (LP), ${ }^{21}$ and 5) the North American Spine Society (NASS) satisfaction questionnaire?

Clinically significant improvement in disability and pain were defined using the concept of minimum clinically important difference (MCID). The MCID represents a critical threshold, compared with the baseline, which is considered a clinically meaningful improvement to the patient. The MCID compares the change in score for a PRO following the intervention to another externally validated measure of outcomes such as perceived improvement or satisfaction following the procedure in question., 5 , Previously published MCID values for the ODI (14.9), NRS-BP (2.1) and NRS-LP (2.8) scores, and the EQ-5D (0.46) were used to dichotomize the patient group based on whether or not MCID was achieved MCID. . $7,28^{2}$

Complications were divided into major (surgical-site infection that required incision and drainage of wound, CSF leaks, hardware failure or wound, new neurological deficit, pulmonary embolism, hematoma, MI, and readmission within 90 days) and minor (superficial surgicalsite infection that was treated with local wound inspection and oral antibiotics, urinary tract infection, pneumonia, and deep venous thrombosis).

\section{Statistical Analysis}

The mean and standard deviation were computed for continuous variables, and frequency was computed for categorical variables. Assuming a mean 12-month ODI of 29 points in patients with complications and 25 points in those without complications and a standard deviation of 17 points, a sample size of 108 would yield $80 \%$ power to detect a significant difference in 12-month ODI outcomes between the 2 groups. Univariate analyses were conducted to determine the association of clinical variables with the presence or absence of complications. The Student ttest and Mann-Whitney U-test were used for continuous data. Nominal data were compared via chi-square test. Multivariable linear regression analyses were conducted, controlling for the array of preoperative patient-specific and surgery-specific variables (see Table 4 for list) with 
12 -month ODI as the outcome variable. A p value $<0.05$ was considered statistically significant. Analyses were performed using SPSS version 20 (IBM Corp.). In the tables, means are presented \pm SD.

\section{Results \\ Patient Demographics}

A total of 906 consecutive patients (443 male and 463 female) were included in the study. Their mean age was 59 \pm 14 years. Twenty-three percent $(n=207)$ had diabetes at the time of surgery. Mean body mass index (BMI) of the cohort was $30.9 \pm 7 \mathrm{~kg} / \mathrm{m}^{2}$. Fifty-four percent of the patients $(n=490)$ had duration of symptoms more than 12 months. The mean baseline scores were as follows: ODI, $48.2 \pm 15.5$ points; back pain, $6.5 \pm 2.7$ points; leg pain, 6.5 \pm 2.9 points; EQ-5D, $0.55 \pm 0.22$ QALY (quality-adjusted life year); SF-12 PCS score, $26.5 \pm 9.2$; and SF-12 MCS score, $48.6 \pm 12.1$ (Table 1). Fifteen percent of patients (n $=139)$ underwent microdiscectomy, $28 \%(\mathrm{n}=255)$ underwent laminectomy alone, and 57\% ( $\mathrm{n}=512)$ underwent laminectomy and fusion. Thirteen percent $(\mathrm{n}=118)$ of patients developed complications: $12 \%(n=108)$ had major complications and 8\% $(n=68)$ had minor complications within 90 days after surgery. Of the total of 118 complications, surgical-site infection $(\mathrm{n}=21,18 \%)$ was the most common major complication followed by new neurological deficit $(\mathrm{n}=12,10 \%)$, whereas urinary tract infection $(\mathrm{n}=61,52 \%)$ was the most common minor complication. Figure 1 summarizes the frequency of each major and minor complication.

\section{Characteristics of Patients Who Developed Major Complications}

Table 1 summarizes the patient-specific and surgeryspecific characteristics of patients with and without ma- jor complications. The patients with major complications, compared with those with no complication, had higher rates of comorbidities, including diabetes $(31 \%$ vs $22 \%$, p $=0.04)$ and hypertension (63\% vs $57 \%, \mathrm{p}=0.03)$. Patients with a major complication were more likely to have Medicaid/uninsured payer status (14\% vs 10\%) or Medicare (40\% vs $29 \%$ ) compared with those without complications $(\mathrm{p}=0.012)$. The rate of complications was higher in patients undergoing decompression with fusion (65\%) compared with decompression only (23\%) and microdiscectomy $(11 \%)(p=0.06)$. Patients with a major complication were more likely to be discharged to inpatient rehabilitation (15\% vs $11 \%)$ and skilled nursing facilities $(7 \%$ vs $2 \%)(\mathrm{p}=0.003)$ compared with patients without major complications.

\section{Outcomes}

The patients with complications had significantly lower improvement in ODI scores $(13.5 \pm 21.2$ vs $21.7 \pm 19$, $\mathrm{p}<0.0001)$, EQ-5D scores $(0.17 \pm 0.25$ vs $0.23 \pm 0.23$, $\mathrm{p}=0.04)$, SF-12 PCS scores $(8.6 \pm 13.3$ vs $13.0 \pm 11.9$, $\mathrm{p}=0.001$ ). The patients with major complications had a significantly lower rate of satisfaction $(76 \%$ vs $90 \%, p=$ 0.002 ) than those without major_complications 3 months after surgery. There was no significant difference in the proportion of preoperatively employed patients who had returned to work at 3 months after surgery among the patients with and without major complications ( $85 \%$ vs. $82 \%$, respectively; $p=0.10$ ). Table 2 summarizes the impact of complications on 3-month PRO scores.

A significant improvement in pain, disability, and quality of life was noted in all patients 12 months after surgery $(\mathrm{p}<0.0001)$. Patients with major complications had significantly higher ODI scores at 12 months after surgery than patients without major complications $(29.1 \pm 17.7$ vs 25.3 $\pm 18.3, \mathrm{p}=0.02$ ) (Table 3). However, there was no differ-

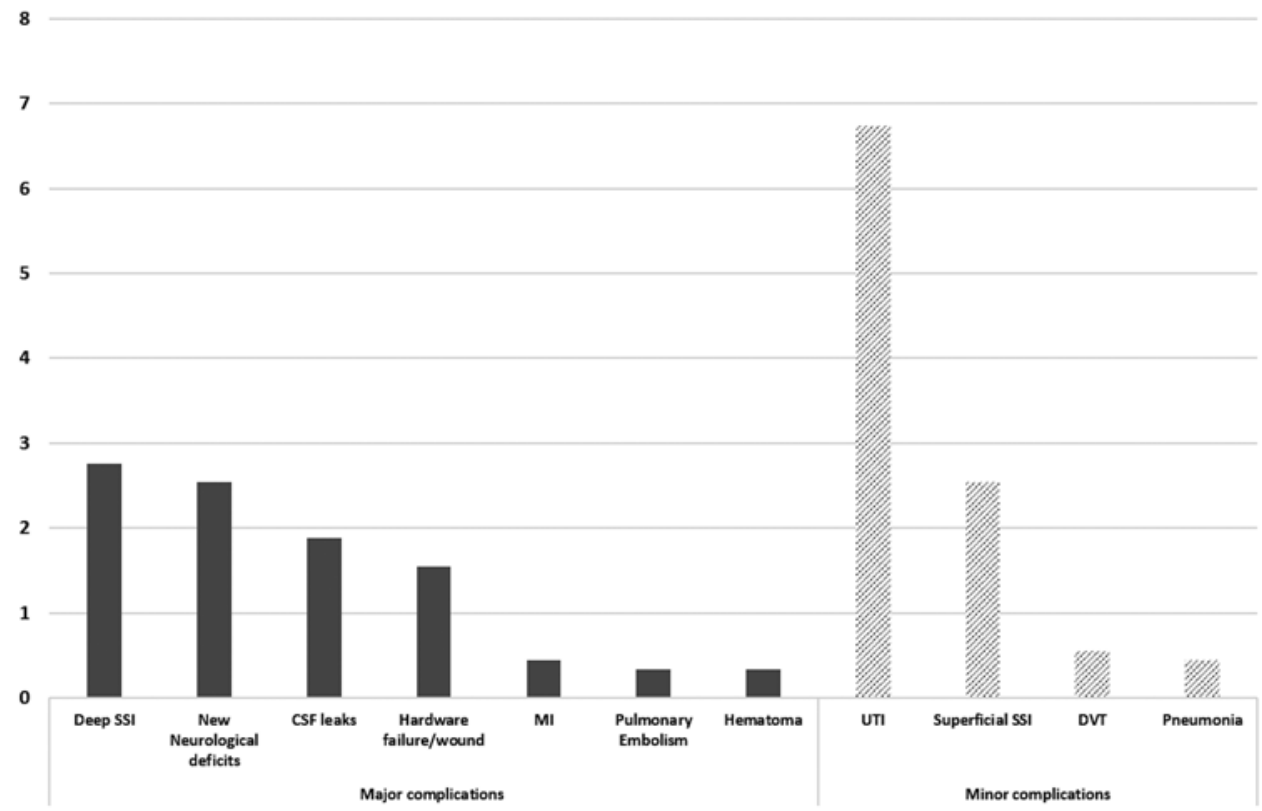

FIG. 1. Frequency (percentage) of complications following lumbar spine surgery. DVT = deep venous thrombosis; SSI = surgicalsite infection; UTI = urinary tract infection. 
TABLE 1. Patient-specific and surgery-specific factors in patients with and without complications*

\begin{tabular}{|c|c|c|c|c|}
\hline \multirow[b]{2}{*}{ Variable } & \multirow[b]{2}{*}{ Total Group } & \multicolumn{2}{|c|}{ Major Complications } & \multirow[b]{2}{*}{$\mathrm{p}$ Value } \\
\hline & & No & Yes & \\
\hline No. of patients & 906 & 798 & 108 & \\
\hline Age in yrs & $59 \pm 14$ & $59 \pm 14$ & $61 \pm 14$ & \\
\hline Sex & & & & 0.26 \\
\hline Male & $443(49)$ & $392(49)$ & $51(47)$ & \\
\hline Female & $463(51)$ & $406(51)$ & $57(53)$ & \\
\hline $\mathrm{BMI}\left(\mathrm{kg} / \mathrm{m}^{2}\right)$ & $30.9 \pm 7$ & $30.8 \pm 6.9$ & $30.4 \pm 6.9$ & 0.67 \\
\hline Smoker & $471(52)$ & $410(51)$ & $61(56)$ & 0.47 \\
\hline ZSDS score & $35.4 \pm 9.6$ & $35.2 \pm 9.2$ & $35.7 \pm 10.2$ & 0.55 \\
\hline MSPQ score & $6.1 \pm 4.7$ & $6.1 \pm 4.6$ & $6.0 \pm 4.8$ & 0.93 \\
\hline Preop narcotic use & $498(55)$ & $434(54)$ & $64(59)$ & 0.44 \\
\hline Prior surgery & $259(29)$ & $228(29)$ & $31(29)$ & 0.53 \\
\hline ASA grade & & & & 0.43 \\
\hline 1 & $35(4)$ & $32(4)$ & $3(3)$ & \\
\hline 2 & $293(32)$ & $259(32)$ & $34(31)$ & \\
\hline 3 or 4 & $578(64)$ & $507(64)$ & $69(64)$ & \\
\hline BP dominant & $52(6)$ & $44(6)$ & $8(7)$ & 0.27 \\
\hline BP \& LP equal & $612(68)$ & $550(69)$ & $62(57)$ & $0.012 \dagger$ \\
\hline LP dominant & $151(17)$ & $135(17)$ & $16(15)$ & 0.34 \\
\hline Duration of symptoms & & & & $0.008 \dagger$ \\
\hline$<3$ mos & $98(11)$ & $77(10)$ & $21(19)$ & \\
\hline $3-12$ mos & $318(35)$ & $285(36)$ & $33(31)$ & \\
\hline$>12$ mos & $490(54)$ & $436(55)$ & $54(50)$ & \\
\hline Myelopathy & $37(4)$ & $32(4)$ & $5(5)$ & 0.46 \\
\hline Neurogenic claudication & $196(22)$ & $171(21)$ & $25(23)$ & 0.38 \\
\hline \multicolumn{5}{|l|}{ Comorbidities } \\
\hline History of arthritis & $604(67)$ & $531(67)$ & $73(64)$ & 0.27 \\
\hline History of COPD & $33(4)$ & $28(3)$ & $5(5)$ & 0.3 \\
\hline History of $\mathrm{CHF}$ & $26(3)$ & $21(3)$ & $5(5)$ & 0.16 \\
\hline History of diabetes & $207(23)$ & $174(22)$ & $33(31)$ & $0.04 \dagger$ \\
\hline History of hypertension & $529(58)$ & $456(57)$ & $73(63)$ & $0.03 \dagger$ \\
\hline History of MI & $41(5)$ & $35(4)$ & $6(6)$ & 0.33 \\
\hline History of osteoporosis & $20(2)$ & $17(2)$ & $3(3)$ & 0.43 \\
\hline History of preoperative anticoagulation & $22(2)$ & $16(2)$ & $6(6)$ & $0.04 \dagger$ \\
\hline \multicolumn{5}{|l|}{ Diagnosis $(\mathrm{n}[\%])$} \\
\hline Herniated disc & $229(25)$ & $204(26)$ & $25(23)$ & \\
\hline Spondylolisthesis & $266(29)$ & $233(29)$ & $33(31)$ & \\
\hline Stenosis & $411(45)$ & $361(45)$ & $50(46)$ & \\
\hline Insurance type & & & & $0.012 \dagger$ \\
\hline Medicaid/uninsured & 95 & $80(10)$ & $15(14)$ & \\
\hline Medicare & 272 & $229(29)$ & $43(40)$ & \\
\hline Private & 539 & $489(61)$ & $50(46)$ & \\
\hline Surgery & & & & 0.06 \\
\hline Microdiscectomy & $139(15)$ & $127(16)$ & $12(11)$ & \\
\hline Laminectomy & $255(28)$ & $229(29)$ & $26(23)$ & \\
\hline Laminectomy \& fusion & $512(57)$ & $442(55)$ & $70(65)$ & \\
\hline Length of hospital stay in days & $3.7 \pm 4.3$ & $3.25 \pm 5.5$ & $4.0 \pm 3.0$ & 0.17 \\
\hline Length of surgery in minutes & $193.1 \pm 83.9$ & $183.3 \pm 84.6$ & $203.1 \pm 83.1$ & 0.02 \\
\hline
\end{tabular}


TABLE 1. Patient-specific and surgery-specific factors in patients with and without complications* (continued)

\begin{tabular}{lcccc}
\hline & & \multicolumn{2}{c}{ Major Complications } & \\
\cline { 3 - 4 } Variable & Total Group & No & Yes & $p$ Value \\
\hline No. of levels operated & $1.8 \pm 0.91$ & $1.71 \pm 0.85$ & $1.87 \pm 0.98$ & 0.07 \\
\hline Baseline PROS & & & & \\
\hline ODI & $48.2 \pm 15.5$ & $48.1 \pm 15.1$ & $48.9 \pm 17.1$ & 0.58 \\
\hline NRS-BP & $6.5 \pm 2.7$ & $6.5 \pm 2.6$ & $6.8 \pm 2.6$ & 0.22 \\
\hline NRS-LP & $6.5 \pm 2.9$ & $6.7 \pm 2.8$ & $6.7 \pm 3.1$ & 0.96 \\
\hline SF-12 MCS & $48.6 \pm 12.1$ & $48.5 \pm 11.7$ & $48.9 \pm 12.5$ & 0.89 \\
\hline SF-12 PCS & $26.5 \pm 9.2$ & $26.8 \pm 9.1$ & $26.3 \pm 9.4$ & 0.59 \\
\hline EQ-5D & $0.55 \pm 0.22$ & $0.55 \pm 0.27$ & $0.54 \pm 0.21$ & 0.71 \\
\hline
\end{tabular}

$\mathrm{CHF}=$ congestive heart failure; $\mathrm{COPD}=$ chronic obstructive pulmonary disease; $\mathrm{MSPQ}=$ modified somatic perception questionnaire; $Z$ SDS =

Zung Self-Rating Depression Scale.

* Data are presented as numbers of patients (\%) unless otherwise indicated. Mean values are presented with SDs.

† Statistically significant.

ence in the change scores in ODI or in the absolute scores across the other PROs between the 2 groups at 12 months following surgery. None of the major complications significantly affected the PROs 12 months after surgery. Figure 2 demonstrates improvement in pain, disability, and

TABLE 2. Impact of complications on short-term (3-month) patient-reported outcome scores

\begin{tabular}{|c|c|c|c|}
\hline \multirow[b]{2}{*}{ Variable } & \multicolumn{2}{|c|}{ Major Complications } & \multirow[b]{2}{*}{$p$ Value } \\
\hline & No & Yes & \\
\hline No. of patients & 798 & 108 & \\
\hline \multicolumn{4}{|c|}{ 3-month PROs (mean \pm SD) } \\
\hline ODI & $26.2 \pm 17.7$ & $35.7 \pm 18.0$ & $<0.0001^{*}$ \\
\hline $\mathrm{BP}$ & $3.0 \pm 2.7$ & $3.7 \pm 2.7$ & $0.014^{*}$ \\
\hline LP & $2.5 \pm 3.0$ & $3.1 \pm 3.0$ & 0.14 \\
\hline EQ-5D & $0.77 \pm 0.19$ & $0.72 \pm 0.18$ & $0.006^{*}$ \\
\hline SF-12 MCS & $53.4 \pm 9.7$ & $51.4 \pm 10.5$ & 0.07 \\
\hline SF-12 PCS & $39.7 \pm 13.2$ & $34.8 \pm 12.2$ & $<0.0001^{*}$ \\
\hline \multicolumn{4}{|c|}{$\begin{array}{l}\text { Change in scores from base- } \\
\text { line (mean } \pm \text { SD) }\end{array}$} \\
\hline ODI & $21.7 \pm 19.0$ & $13.4 \pm 21.2$ & $<0.0001^{*}$ \\
\hline $\mathrm{BP}$ & $3.4 \pm 3.1$ & $3.1 \pm 3.3$ & 0.31 \\
\hline LP & $4.1 \pm 3.8$ & $3.6 \pm 4.1$ & 0.28 \\
\hline$E Q-5 D$ & $0.23 \pm 0.23$ & $0.17 \pm 0.25$ & $0.04^{*}$ \\
\hline SF-12 PCS & $13.0 \pm 11.9$ & $8.6 \pm 13.3$ & $0.001^{*}$ \\
\hline SF-12 MCS & $4.9 \pm 11.8$ & $2.8 \pm 12.9$ & 0.28 \\
\hline Discharge status (n [\%]) & & & $0.003^{*}$ \\
\hline Home & $693(87)$ & $83(77)$ & \\
\hline Inpatient rehab & $87(11)$ & $17(15)$ & \\
\hline SNIF & $18(2)$ & $8(7)$ & \\
\hline Satisfaction (n [\%]) & $714(90)$ & $82(76)$ & $0.002^{*}$ \\
\hline RTW (n [\%])† & 264 (82) & $28(85)$ & 0.10 \\
\hline
\end{tabular}

Rehab = rehabilitation; SNIF = skilled nursing inpatient facility.

* Statistically significant.

$\dagger$ The RTW analysis included patients who were gainfully employed preoperatively $(n=354)$. The rate of RTW within 90 days following surgery was $82 \%$ (292/354) quality-of-life scores from baseline to 3 months and 12 months following surgery in patients with and without major complications, minor complications, new neurological deficits, deep surgical-site infection, CSF leaks, and hardware failure.

In a multivariable linear regression analysis, after controlling for an array of preoperative variables, including baseline ODI scores, back pain and leg pain scores, fusion, revision surgery, smoking, history of diabetes, and preoperative narcotic use, the occurrence of a major complication was not associated with higher 12-month ODI scores (Table 4). There was no difference in the percentage of patients achieving MCID for disability (66\% vs $64 \%, \mathrm{p}=$ $0.33)$, back pain $(55 \%$ vs $56 \%, \mathrm{p}=0.47)$, leg pain $(62 \%$ vs $59 \%, \mathrm{p}=0.35)$, and quality of life $(19 \%$ vs $14 \%, \mathrm{p}=0.17)$ and patient satisfaction rates ( $82 \%$ vs $80 \%, \mathrm{p}=0.12)$ between those without and with major complications.

\section{Discussion}

Patients undergoing lumbar surgery are at increased risk of perioperative complications, which might have an impact on long-term outcomes. In this analysis, utilizing a prospective longitudinal registry, we demonstrated that perioperative complications have an impact on short-term (3-month) outcomes following lumbar spine surgery; however, after controlling for potential confounders, the occurrence of major complications following lumbar spine surgery was not associated with more severe disability 12 months after surgery. Furthermore, patients who experienced major complications within the first 90 days after lumbar surgery achieved clinically meaningful benefit in disability, pain, and quality-of-life outcomes and satisfaction at 12 months as much as those without major complications.

Previous studies have reported the effect of perioperative complications on long-term PROs after lumbar fusion surgery ${ }^{20}$ or for specific patient characteristics (obesity, diabetes mellitus, advanced age)..$^{3,16}$ Lambat et al. ${ }^{20}$ retrospectively analyzed the impact of perioperative complications on 2-year postoperative outcomes. Analogous to our findings, the authors reported that the disability scores 

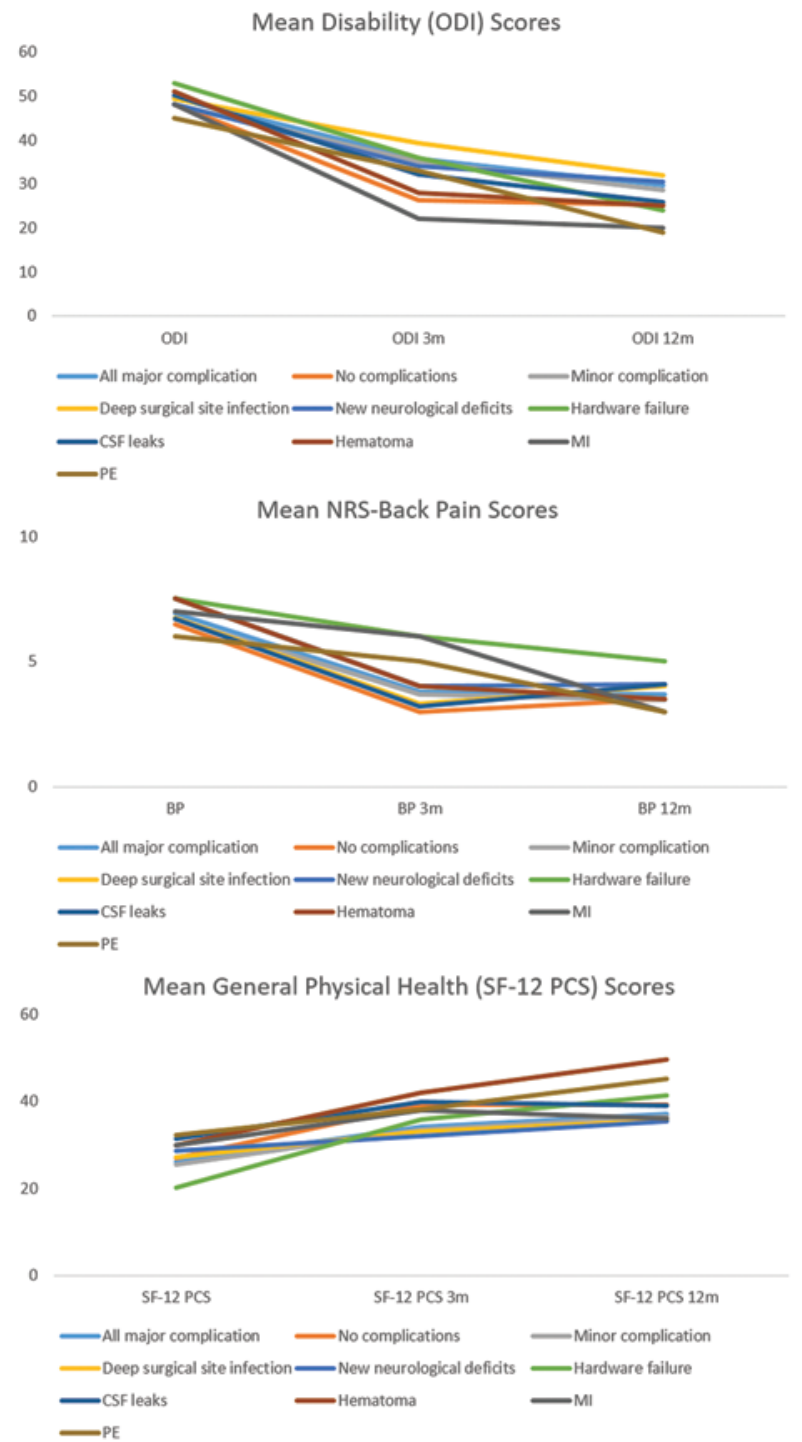
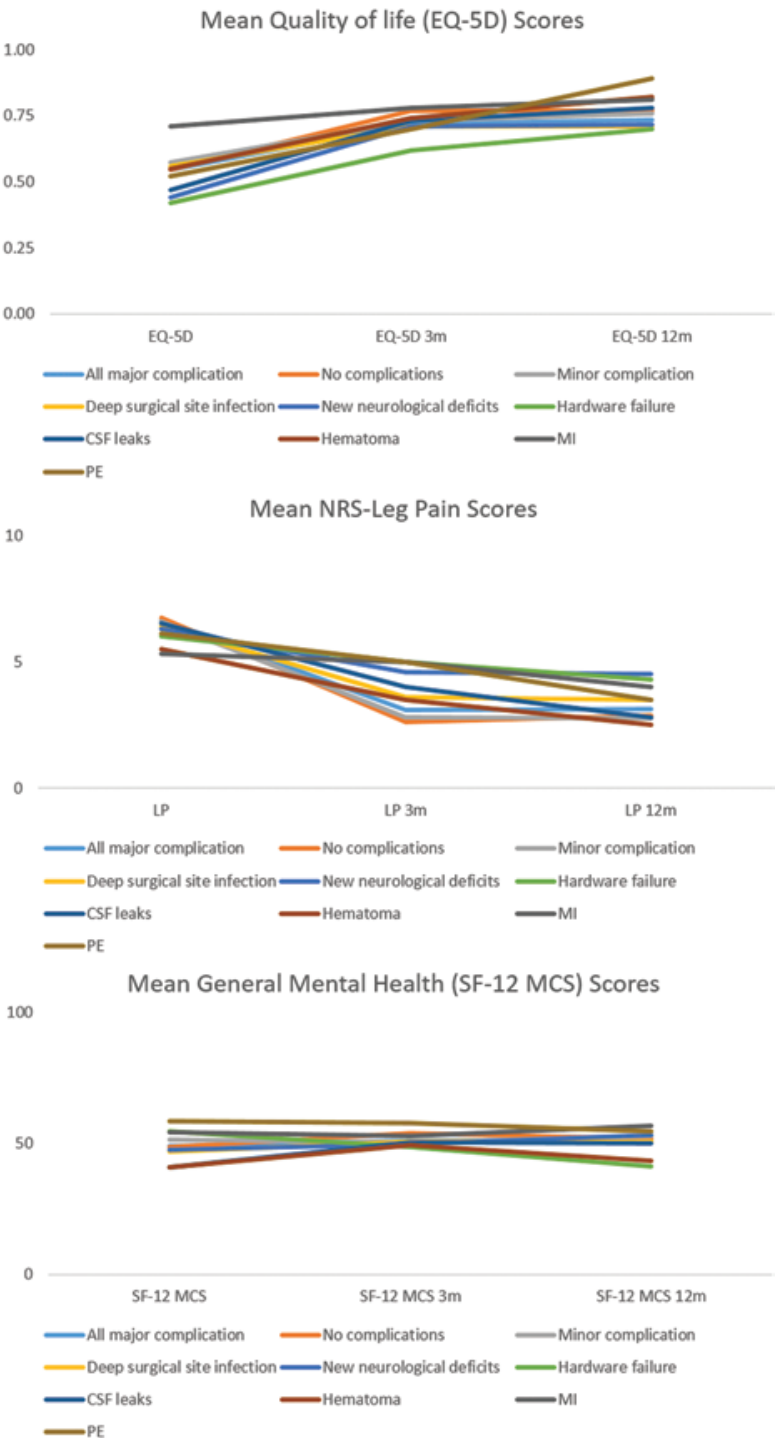

FIG. 2. Comparison of improvement in pain (BP and LP), disability (ODI), and quality of life (EQ-5D and SF-12) from baseline to 3 months and 12 months following surgery in patients with and without major complications, minor complications, new neurological deficits, deep surgical-site infection, CSF leaks, and hardware failure. PE = pulmonary embolism.

were significantly higher in those with major complications compared with the patients with no complications. In our analysis, after controlling for several preoperative variables, the occurrence of major complications was not associated with 12-month outcome following lumbar surgery. Similarly, Juricek et al., ${ }^{18}$ in a retrospective study of 208 patients who underwent fusion procedures for degenerative pathology, reported a complication rate of $13.4 \%$ with a duration of follow-up ranging from 6 months to 2 years. The authors reported no influence of perioperative complications on quality of life or on pain intensity after lumbar fusion surgery. As opposed to the previously reported studies, our analysis was based on a prospectively collected registry data and included patients who had undergone surgeries with different levels of invasiveness: microdiscectomy, laminectomy alone, and laminectomy with fusion, thereby providing more comprehensive data on the impact of complications on PROs for treatment of degenerative lumbar spine diseases. Among the major complications, surgical-site infection and new neurological deficits were the most frequently observed complications within 90 days following surgery. There was no significant difference in the PROs 12 months following surgery among the patients who developed any of the major complications. The rate of postoperative complications following lumbar spine surgery reported in the literature varies widely, from approximately as low as $3 \%$ to as high as $50 \%$. $4,14,26,36$ The incidence of major complications in our study was $12 \%$. This wide range is due to the discrepancy in classifying the complications into major or minor complications, timing of complications (30 days vs 90 days vs 1 year) and retrospective versus prospective study design. . $^{3,12,15,25,26,36}$ A standardized definition of a major complication will allow for comparison across the reported studies. 
TABLE 3. Impact of major complications on long-term (12-month) patient-reported outcomes*

\begin{tabular}{|c|c|c|c|}
\hline \multirow[b]{2}{*}{ Group \& Outcome Measure } & \multicolumn{2}{|c|}{ Major Complications } & \multirow[b]{2}{*}{$\mathrm{p}$ Value } \\
\hline & No & Yes & \\
\hline \multicolumn{4}{|l|}{ All patients } \\
\hline No. of patients & 798 & 108 & \\
\hline \multicolumn{4}{|l|}{ 12-mo PROs (mean \pm SD) } \\
\hline ODI & $25.3 \pm 18.3$ & $29.1 \pm 17.7$ & $0.02^{*}$ \\
\hline $\mathrm{BP}$ & $3.5 \pm 3.0$ & $3.6 \pm 2.8$ & 0.61 \\
\hline LP & $2.9 \pm 3.2$ & $3.2 \pm 3.2$ & 0.69 \\
\hline EQ-5D & $0.77 \pm 0.20$ & $0.74 \pm 0.17$ & 0.13 \\
\hline SF-12 MCS & $51.8 \pm 10.7$ & $51.8 \pm 9.9$ & 0.98 \\
\hline SF-12 PCS & $39.1 \pm 13.2$ & $37.4 \pm 12.9$ & 0.13 \\
\hline \multicolumn{4}{|c|}{ Change in scores from baseline (mean $\pm \mathrm{SD}$ ) } \\
\hline ODI & $22.5 \pm 19.9$ & $19.9 \pm 19.3$ & 0.20 \\
\hline $\mathrm{BP}$ & $2.9 \pm 3.5$ & $3.1 \pm 3.3$ & 0.63 \\
\hline LP & $3.8 \pm 3.9$ & $3.5 \pm 4.4$ & 0.50 \\
\hline$E Q-5 D$ & $0.22 \pm 0.26$ & $0.20 \pm 0.25$ & 0.43 \\
\hline SF-12 MCS & $3.2 \pm 14.7$ & $2.8 \pm 11.1$ & 0.72 \\
\hline SF-12 PCS & $12.3 \pm 13.1$ & $11.0 \pm 14.6$ & 0.41 \\
\hline \multicolumn{4}{|l|}{ No. of patients (\%) achieving MCID } \\
\hline ODI & $530(66)$ & $69(64)$ & 0.33 \\
\hline $\mathrm{BP}$ & $436(55)$ & $60(56)$ & 0.47 \\
\hline LP & $492(62)$ & $64(59)$ & 0.35 \\
\hline$E Q-5 D$ & $153(19)$ & $16(5)$ & 0.17 \\
\hline Satisfaction (n [\%]) & $655(82)$ & $86(80)$ & 0.12 \\
\hline \multicolumn{4}{|l|}{ Decompression alone } \\
\hline No. of patients & 356 & 38 & \\
\hline \multicolumn{4}{|l|}{ 12-mo PROs (mean \pm SD) } \\
\hline ODI & $22.4 \pm 18.1$ & $26.4 \pm 14.5$ & 0.13 \\
\hline $\mathrm{BP}$ & $3.1 \pm 3.0$ & $3.9 \pm 2.6$ & 0.06 \\
\hline LP & $2.8 \pm 3.2$ & $3.1 \pm 2.8$ & 0.52 \\
\hline$E Q-5 D$ & $0.87 \pm 0.27$ & $0.87 \pm 0.28$ & 0.97 \\
\hline SF-12 MCS & $52.3 \pm 10.2$ & $50.9 \pm 9.6$ & 0.38 \\
\hline SF-12 PCS & $41.0 \pm 13.6$ & $38.3 \pm 13.1$ & 0.23 \\
\hline \multicolumn{4}{|c|}{ Change in scores from baseline (mean \pm SD) } \\
\hline ODI & $25.2 \pm 21.8$ & $20.2 \pm 22.7$ & 0.20 \\
\hline $\mathrm{BP}$ & $2.9 \pm 3.9$ & $2.2 \pm 3.4$ & 0.16 \\
\hline LP & $3.8 \pm 3.9$ & $3.5 \pm 4.4$ & 0.27 \\
\hline$E Q-5 D$ & $0.25 \pm 0.27$ & $0.19 \pm 0.24$ & 0.18 \\
\hline SF-12 MCS & $4.0 \pm 14.3$ & $3.5 \pm 10.9$ & 0.79 \\
\hline SF-12 PCS & $13.8 \pm 14.5$ & $9.6 \pm 15.6$ & 0.11 \\
\hline \multicolumn{4}{|l|}{ No. of patients (\%) achieving MCID } \\
\hline ODI & $245(69)$ & $25(66)$ & 0.41 \\
\hline MCID BP & $198(56)$ & $18(47)$ & 0.21 \\
\hline MCID LP & $229(64)$ & $21(55)$ & 0.12 \\
\hline MCID EQ-5D & $83(23)$ & $5(13)$ & 0.12 \\
\hline Satisfaction (n [\%]) & $261(73)$ & $26(68)$ & 0.19 \\
\hline
\end{tabular}


TABLE 3. Impact of major complications on long-term (12-month) patient-reported outcomes* (continued)

\begin{tabular}{|c|c|c|c|}
\hline \multirow[b]{2}{*}{ Group \& Outcome Measure } & \multicolumn{2}{|c|}{ Major Complications } & \multirow[b]{2}{*}{ p Value } \\
\hline & No & Yes & \\
\hline \multicolumn{4}{|l|}{ Decompression \& fusion } \\
\hline No. of patients & 440 & 70 & \\
\hline \multicolumn{4}{|l|}{ 12-mo PROs (mean $\pm \mathrm{SD}$ ) } \\
\hline ODI & $27.7 \pm 18.2$ & $30.6 \pm 19.2$ & 0.23 \\
\hline $\mathrm{BP}$ & $3.9 \pm 3.0$ & $3.6 \pm 2.9$ & 0.42 \\
\hline $\mathrm{LP}$ & $3.0 \pm 3.2$ & $3.2 \pm 3.5$ & 0.55 \\
\hline$E Q-5 D$ & $0.87 \pm 0.33$ & $0.84 \pm 0.37$ & 0.58 \\
\hline SF-12 MCS & $51.2 \pm 11.1$ & $52.3 \pm 10.1$ & 0.44 \\
\hline SF-12 PCS & $37.6 \pm 12.8$ & $36.9 \pm 12.9$ & 0.66 \\
\hline \multicolumn{4}{|c|}{ Change in scores from baseline (mean \pm SD) } \\
\hline ODI & $20.4 \pm 18.0$ & $19.7 \pm 17.9$ & 0.75 \\
\hline $\mathrm{BP}$ & $3.0 \pm 3.3$ & $3.7 \pm 3.2$ & 0.09 \\
\hline LP & $3.6 \pm 3.9$ & $3.6 \pm 4.9$ & 0.95 \\
\hline$E Q-5 D$ & $0.20 \pm 0.24$ & $0.20 \pm 0.25$ & 0.83 \\
\hline SF-12 MCS & $2.7 \pm 12.0$ & $2.5 \pm 11.6$ & 0.87 \\
\hline SF-12 PCS & $11.0 \pm 12.4$ & $11.8 \pm 14.1$ & 0.65 \\
\hline \multicolumn{4}{|l|}{ No. of patients (\%) achieving MCID } \\
\hline ODI & $285(65)$ & $44(63)$ & 0.44 \\
\hline $\mathrm{BP}$ & $238(54)$ & $42(60)$ & 0.20 \\
\hline LP & $263(60)$ & $43(61)$ & 0.43 \\
\hline$E Q-5 D$ & $70(16)$ & $11(16)$ & 0.57 \\
\hline Satisfaction (n [\%]) & $362(82)$ & $54(77)$ & 0.26 \\
\hline
\end{tabular}

None of the previous studies have reported the effect of complications on patient satisfaction. From the societal and patients' perspective the occurrence of complications has personal and economic consequences, resulting in undue stress and frustration for family and patients, portending a lower quality of life and overall increased cost associated with surgery. Therefore, one would assume that the occurrence of complications might affect overall long-term patient satisfaction. However, we found that even though the occurrence of major complications had a significant impact on short-term satisfaction there was no significant difference in 12-month satisfaction rates between those with complications and those without.

All stakeholders, including providers, third-party payers, and CMS (Centers for Medicare \& Medicaid Services), have placed an emphasis on reducing complications and associated readmissions to improve the quality of spine care. Physicians are being penalized for readmission and certain complications, which directly affects physician reimbursement. In this analysis, we used several pragmatic

TABLE 4. Multivariable linear regression model to determine the effect of complication on the 12-month absolute ODI scores

\begin{tabular}{lcccc}
\hline & & & \multicolumn{2}{c}{$95.0 \% \mathrm{Cl}$} \\
\cline { 4 - 5 } Variable & Beta Coefficient & $\mathrm{p}$ Value & Lower Bound & Upper Bound \\
\hline (Constant) & 1.265 & 0.635 & -3.962 & 6.492 \\
\hline Major complications & -0.681 & 0.661 & -3.732 & 2.369 \\
\hline Baseline ODI score & 0.453 & $<0.0001$ & 0.391 & 0.515 \\
\hline Baseline BP score & 0.436 & 0.030 & 0.042 & 0.830 \\
\hline Revision surgery & 4.692 & $<0.0001$ & 2.468 & 6.917 \\
\hline Smoker & 1.277 & 0.207 & -0.709 & 3.262 \\
\hline Preoperative narcotic use & 2.411 & 0.021 & 0.363 & 4.459 \\
\hline Surgery & 0.072 & 0.920 & -1.324 & 1.468 \\
\hline History of diabetes & 1.256 & 0.294 & -1.094 & 3.606 \\
\hline Total ZSDS sum score & 0.082 & 0.220 & -0.049 & 0.214 \\
\hline Total MSPQ sum score & 0.477 & $<0.001$ & 0.209 & 0.746 \\
\hline
\end{tabular}


metrics including validated PROs, clinically meaningful thresholds, and patient satisfaction to comprehensively determine the impact of complications on overall outcomes. Based on our analysis and other reported studies, complications do not seem to have a significant impact on longterm outcomes following lumbar spine surgery.

This study is not without limitations. The study was powered to detect the difference in the 12-month outcomes in patients with and without major complications. The number of patients with each complication was small making it difficult to analyze the effect of each complication on outcomes. We, however, found that there was no significant impact of the most frequent major complications on outcomes. The association of complications and outcomes is complex and multifactorial, it is important to account for the factors that might confound the effect of complications on outcomes. We report a well-designed study, utilizing comprehensive and granular variables captured in our prospective longitudinal registry, for risk-adjusted analysis for impact of complications on the PROs. The potential confounding variables included in our analysis are not exhaustive and adding more variables and longer follow-up might change the impact of complications on outcomes. Furthermore, this is a single institution study and its results cannot be generalized and extrapolated to the entire population. Perhaps in other institutions complications would not be managed as well and may impact long-term outcomes. The applicability of these data for patient counseling needs to take this limitation into account. Therefore, the further analysis using multicenter longitudinal registries such as the National Neurosurgery Quality Outcomes Database ( $\left.\mathrm{N}^{2} \mathrm{QOD}\right)$ is imperative.

\section{Conclusions}

Major complications occurring within 90 days following lumbar spine surgery have a significant impact on shortterm PROs. Patients with major complications, however, achieve clinically meaningful long-term outcomes and patient satisfaction, as much as those without major complications. This information allows a physician to counsel patients on the fact that a complication creates frustration, cost, and inconvenience; however, it does not appear to adversely affect clinically meaningful long-term outcomes and satisfaction.

\section{References}

1. Bekelis K, Desai A, Bakhoum SF, Missios S: A predictive model of complications after spine surgery: the National Surgical Quality Improvement Program (NSQIP) 2005-2010. Spine J 14:1247-1255, 2014

2. Campbell PG, Yadla S, Nasser R, Malone J, Maltenfort MG, Ratliff JK: Patient comorbidity score predicting the incidence of perioperative complications: assessing the impact of comorbidities on complications in spine surgery. J Neurosurg Spine 16:37-43, 2012

3. Carreon LY, Puno RM, Dimar JR, II, Glassman SD, Johnson JR: Perioperative complications of posterior lumbar decompression and arthrodesis in older adults. J Bone Joint Surg Am 85-A:2089-2092, 2003

4. Cassinelli EH, Eubanks J, Vogt M, Furey C, Yoo J, Bohlman $\mathrm{HH}$ : Risk factors for the development of perioperative complications in elderly patients undergoing lumbar decompres- sion and arthrodesis for spinal stenosis: an analysis of 166 patients. Spine (Phila Pa 1976) 32:230-235, 2007

5. Copay AG, Glassman SD, Subach BR, Berven S, Schuler TC, Carreon LY: Minimum clinically important difference in lumbar spine surgery patients: a choice of methods using the Oswestry Disability Index, Medical Outcomes Study questionnaire Short Form 36, and pain scales. Spine J 8:968-974, 2008

6. Dagenais S, Caro J, Haldeman S: A systematic review of low back pain cost of illness studies in the United States and internationally. Spine J 8:8-20, 2008

7. Daltroy LH, Cats-Baril WL, Katz JN, Fossel AH, Liang MH: The North American spine society lumbar spine outcome assessment Instrument: reliability and validity tests. Spine (Phila Pa 1976) 21:741-749, 1996

8. Deyo RA, Gray DT, Kreuter W, Mirza S, Martin BI: United States trends in lumbar fusion surgery for degenerative conditions. Spine (Phila Pa 1976) 30:1441-1447, 2005

9. EuroQol Group: EuroQol-a new facility for the measurement of health-related quality of life. Health Policy 16:199208, 1990

10. Faciszewski T, Winter RB, Lonstein JE, Denis F, Johnson L: The surgical and medical perioperative complications of anterior spinal fusion surgery in the thoracic and lumbar spine in adults. A review of 1223 procedures. Spine (Phila Pa 1976) 20:1592-1599, 1995

11. Fairbank JC, Pynsent PB: The Oswestry Disability Index. Spine (Phila Pa 1976) 25:2940-2952, 2000

12. Fritzell $P$, Hägg $\mathrm{O}$, Nordwall A: Complications in lumbar fusion surgery for chronic low back pain: comparison of three surgical techniques used in a prospective randomized study. A report from the Swedish Lumbar Spine Study Group. Eur Spine J 12:178-189, 2003

13. Frymoyer JW, Cats-Baril WL: An overview of the incidences and costs of low back pain. Orthop Clin North Am 22:263271, 1991

14. Glassman SD, Alegre G, Carreon L, Dimar JR, Johnson JR: Perioperative complications of lumbar instrumentation and fusion in patients with diabetes mellitus. Spine J 3:496-501, 2003

15. Glassman SD, Hamill CL, Bridwell KH, Schwab FJ, Dimar JR, Lowe TG: The impact of perioperative complications on clinical outcome in adult deformity surgery. Spine (Phila Pa 1976) 32:2764-2770, 2007

16. Guzman JZ, Iatridis JC, Skovrlj B, Cutler HS, Hecht AC, Qureshi SA, et al: Outcomes and complications of diabetes mellitus on patients undergoing degenerative lumbar spine surgery. Spine (Phila Pa 1976) 39:1596-1604, 2014

17. Hoffman RM, Wheeler KJ, Deyo RA: Surgery for herniated lumbar discs: a literature synthesis. J Gen Intern Med 8:487-496, 1993

18. Jurícek M, Rehák L, Tisovský P, Horváth J: [The effect of complications on the quality of life after surgery for lumbar spine degenerative disease.] Acta Chir Orthop Traumatol Cech 77:112-117, 2010 (Slovak)

19. Kim BD, Smith TR, Lim S, Cybulski GR, Kim JY: Predictors of unplanned readmission in patients undergoing lumbar decompression: multi-institutional analysis of 7016 patients. J Neurosurg Spine 20:606-616, 2014

20. Lambat MP, Glassman SD, Carreon LY: Impact of perioperative complications on clinical outcome scores in lumbar fusion surgery. J Neurosurg Spine 18:265-268, 2013

21. Langley GB, Sheppeard H: The visual analogue scale: its use in pain measurement. Rheumatol Int 5:145-148, 1985

22. Lohr KN, Schroeder SA: A strategy for quality assurance in Medicare. N Engl J Med 322:707-712, 1990

23. Martin BI, Deyo RA, Mirza SK, Turner JA, Comstock BA, Hollingworth W, et al: Expenditures and health status among adults with back and neck problems. JAMA 299:656-664, 2008 
24. Martin BI, Turner JA, Mirza SK, Lee MJ, Comstock BA, Deyo RA: Trends in health care expenditures, utilization, and health status among US adults with spine problems, 19972006. Spine (Phila Pa 1976) 34:2077-2084, 2009

25. McCutcheon BA, Ciacci JD, Marcus LP, Noorbakhsh A, Gonda DD, McCafferty R, et al: Thirty-day perioperative outcomes in spinal fusion by specialty within the NSQIP database. Spine (Phila Pa 1976) 40:1122-1131, 2015

26. Nasser R, Yadla S, Maltenfort MG, Harrop JS, Anderson DG, Vaccaro AR, et al: Complications in spine surgery. J Neurosurg Spine 13:144-157, 2010

27. Parker SL, Adogwa O, Paul AR, Anderson WN, Aaronson $\mathrm{O}$, Cheng JS, et al: Utility of minimum clinically important difference in assessing pain, disability, and health state after transforaminal lumbar interbody fusion for degenerative lumbar spondylolisthesis. J Neurosurg Spine 14:598-604, 2011

28. Parker SL, Godil SS, Shau DN, Mendenhall SK, McGirt MJ: Assessment of the minimum clinically important difference in pain, disability, and quality of life after anterior cervical discectomy and fusion: clinical article. J Neurosurg Spine 18:154-160, 2013

29. Parker SL, Shau DN, Mendenhall SK, McGirt MJ: Factors influencing 2-year health care costs in patients undergoing revision lumbar fusion procedures. J Neurosurg Spine 16:323-328, 2012

30. Schwender JD, Casnellie MT, Perra JH, Transfeldt EE, Pinto MR, Denis F, et al: Perioperative complications in revision anterior lumbar spine surgery: incidence and risk factors. Spine (Phila Pa 1976) 34:87-90, 2009

31. Tosteson AN, Skinner JS, Tosteson TD, Lurie JD, Andersson GB, Berven S, et al: The cost effectiveness of surgical versus nonoperative treatment for lumbar disc herniation over two years: evidence from the Spine Patient Outcomes Research Trial (SPORT). Spine (Phila Pa 1976) 33:2108-2115, 2008

32. Turner JA, Loeser JD, Deyo RA, Sanders SB: Spinal cord stimulation for patients with failed back surgery syndrome or complex regional pain syndrome: a systematic review of effectiveness and complications. Pain 108:137-147, 2004

33. Wang MY, Green BA, Shah S, Vanni S, Levi AD: Complications associated with lumbar stenosis surgery in patients older than 75 years of age. Neurosurg Focus 14(2):e7, 2003

34. Ware J Jr, Kosinski M, Keller SD: A 12-Item Short-Form
Health Survey: construction of scales and preliminary tests of reliability and validity. Med Care 34:220-233, 1996

35. Weinstein JN, Lurie JD, Tosteson TD, Zhao W, Blood EA, Tosteson AN, et al: Surgical compared with nonoperative treatment for lumbar degenerative spondylolisthesis. Fouryear results in the Spine Patient Outcomes Research Trial (SPORT) randomized and observational cohorts. J Bone Joint Surg Am 91:1295-1304, 2009

36. Yadla S, Malone J, Campbell PG, Maltenfort MG, Harrop JS, Sharan AD, et al: Early complications in spine surgery and relation to preoperative diagnosis: a single-center prospective study. J Neurosurg Spine 13:360-366, 2010

\section{Disclosures}

Dr. McGirt reports receiving consultancy fees from Pacira, DJO, Depuy, Intrinsic, and Stryker. Dr. Devin reports receiving research grants from Stryker Spine and the National Institute of Arthritis and Musculoskeletal Disease and consultancy fees from Depuy for being an exponent consultant for research design and defense expert witness. Dr. Asher owns stock in Hyperbranch Medical Technology and serves as a consultant for Medtronic and Stryker. The other authors have no personal, financial, or institutional interest in any of the drugs, materials, or devices described in this article.

\section{Author Contributions}

Conception and design: Devin, Chotai, Parker, Sivaganesan, Asher, McGirt. Acquisition of data: Chotai. Analysis and interpretation of data: Chotai, Parker, Sivaganesan. Drafting the article: Devin, Chotai. Critically revising the article: all authors. Reviewed submitted version of manuscript: all authors. Approved the final version of the manuscript on behalf of all authors: Devin. Statistical analysis: Chotai. Study supervision: Devin, Asher, McGirt.

\section{Correspondence}

Clinton J. Devin, Department of Orthopaedic Surgery, Vanderbilt Spine Institute, Vanderbilt University School of Medicine, Medical Center East, South Tower, Ste. 4200, Nashville, TN 372328774.email: clinton.j.devin@vanderbilt.edu. 